Canadian

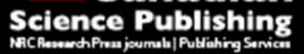

Canadian Journal of Civil Engineering Revue canadienne de génie civil

\title{
An investigation on the effects of flaky particles on the properties of asphaltic mixtures
}

\begin{tabular}{|r|l|}
\hline Journal: & Canadian Journal of Civil Engineering \\
\hline Manuscript ID & cjce-2014-0458.R1 \\
\hline Manuscript Type: & Article \\
\hline Complete List of Authors: & $\begin{array}{l}\text { Kazemi Darabadi, Babak; University of Moghaddase Ardabili, Civil } \\
\text { Engineering Department } \\
\text { Taherkhani, Hasan; University of Zanjan, Civil Engineering Department }\end{array}$ \\
\hline Keyword: & $\begin{array}{l}\text { material properties (MP) < Engineering Materials, highways < } \\
\text { Transportation }\end{array}$ \\
\hline \multicolumn{2}{|c}{} \\
\hline
\end{tabular}




\title{
An investigation on the effects of flaky particles on the properties of asphaltic mixtures
}

\author{
Babak Kazemi Darabadi ${ }^{\text {a, }}$, Hasan Taherkhani ${ }^{\text {b }}$ \\ a, Lecturer, Civil Engineering Department, University of Moghaddase Ardabili, Ardabil, Iran \\ ${ }^{b}$ Assistant Professor, Civil Engineering Department, University of Zanjan, Zanjan, Iran
}

* Corresponding Author: Babak Kazemi Darabadi

Address: Civil Engineering Department, University of Moghaddase Ardabili, Ardabil, Iran

Tel: +989371163192 Fax:+984533721128 Email: babak.msi@gmail.com

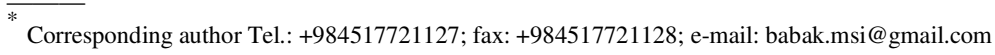


Abstract

Flaky particles, because of their shape, are considered as inferior aggregates in asphaltic mixtures, and specifications usually set limits on the amount of flaky particles in asphaltic mixtures. In this study, the effects of flaky particles content on the volumetric properties, Marshall Stability and creep behaviour of hot mixed asphaltic concrete have been investigated. Specimens with two different types of gradation and specified amounts of flaky particles were made and used for Marshall Stability and static creep tests. Test results show that the Marshall Stability decreases and the air voids content of asphaltic mixture and the voids in mineral aggregate (VMA) increase as the flaky particles content increases. It is also found that flaky particles cause increase in permanent deformation and decrease in creep stiffness. The creep tests also show that the recoverable deformation of the mixtures decreases as the flaky particles content increases.

Keywords: flakiness, aggregates, asphaltic concrete, creep, marshal stability. 


\section{Introduction}

Hot mixed asphaltic concrete is extensively used as the surface course of flexible pavements worldwide. Asphaltic concrete is a very sensitive composite material that a small variation of its components can affect its behaviour. Under traffic loading and environmental effects, different types of distresses can occur in an asphaltic pavement, and resistance of an asphaltic pavement to these distresses significantly depends on the quality and proportions of the constituents. Aggregate and bitumen are the two main components of asphaltic mixtures. Poor quality of each of these materials may lead to the occurrence of premature distresses in asphaltic pavement.

Aggregates constitute between $80 \%$ and $90 \%$ of the total volume of asphaltic concrete and play a key role in the stiffness and bearing capacity of the mixture. In terms of size, aggregates are usually divided into two different classes of coarse and fine. The specification is also divided into two parts: consensus aggregate properties and source aggregate properties. Consensus aggregate properties consists of angularity, flat and elongated particles and clay content and source aggregate properties consists of abrasion, soundness and deleterious materials (Prowell, Zhang, and Brown 2005).

Although a number of researchers have investigated the effects of aggregate characteristics on asphaltic mixtures behaviour, this issue needs more investigations.

One of the main properties of asphaltic mixtures is the creep behaviour, which is directly related to the permanent deformation and rutting of asphaltic pavements. Creep of asphaltic mixtures is dominated by characteristics of their constituents, namely aggregate and bitumen.

In this research, the effects of flaky particles content on some engineering properties of typical asphaltic concrete are investigated.

\section{Literature Review}

Aggregates of asphaltic mixtures are usually produced by crushing rocks. Different shapes of aggregates are produced during the process of crushing. Aggregate particles can be defined in terms of three independent shape properties: shape (or form), angularity, and surface texture as shown in Figure 1 (Barrett 1980; Masad, Little, 
Tashman, Saadeh, Al-Rousan, and Sukhwani 2003). The shape of aggregates is specified by the ratio of dimensions. From the view of shape, aggregates are divided into: round, cubical, flaky and elongated categories. Flaky particles are those which one of whose dimensions is much smaller than the others.

According to BS 812 Part 105.1 aggregate particles are considered as flaky when they have a thickness less than 0.6 of their mean sieve size. The mean sieve size is the average opening size of two successive sieves that particle passes through one and remains on the other. Also, according to ASTM D4791, flaky particles are those with a ratio of width to thickness greater than a specific value.

Presence of flaky particles in asphaltic mixtures is not desirable and may inversely affect the performance of mixture. Thus, specifications have set limitations on the amount of such particles in the asphaltic mixtures. Superpave specification limits the amount of flaky and elongated particles to $10 \%$ for the highway with traffic volume more than 1 million equivalent standard axle load (ESALs) in the designed period of time (Cominsky 1994).

Flaky particles prevent the mixture to compact sufficiently (Roberts, Kandhal, Lee and Kennedy 1991), leading to the increase of air voids in mineral aggregates (VMA) (Brown, McRae, and Crawley 1989; Vavrik, Fries and Carpenter 1999). They are also vulnerable to the crushing during the compaction process and expose uncoated aggregate surfaces (Prowell, Zhang, and Brown 2005). Some researchers have investigated the effect of flaky particles on aggregate breakdown during the compaction process. Brown et al. have performed grading tests on aggregates recovered from an asphaltic mixture that had been compacted with Marshall Apparatus using 50 blows on each side. They found that flaky particles may breakdown significantly during the compaction (Brown, McRae, and Crawley 1989). Vavrik et al. have investigated the fracture of flaky particles during compaction with gyratory apparatus. They used three different types of aggregate: nearly cubical particles with the ratio of width to thickness of less than 3 , particles with a ratio of width to thickness between 3 and 5 and particles with a ratio of width to thickness more than 5 . Their results showed significant changes in the grading of flaky aggregates after compaction (Vavrik, Fries and Carpenter 1999).

Due to their shape, flaky particles are unstable against the applied loads (Figure 2) and tend to produce mixtures with directionally oriented material properties (Tutumluer, Pan, and Carpenter 2005). Oduroh have reported that 
flaky particles with 3:1 ratio in more than $40 \%$ amounts tend to stay horizontal at the mixture due to compaction (Oduroh, Mahboub and Anderson 2000).

There are inconsistent results about the effect of flaky particles on the performance of asphaltic mixtures. Krutz and Sebaaly have found direct relationship between shape and texture of coarse aggregate and rutting potential (Krutz and Sebaaly 1993) though Li and Kett had resulted that, flaky and elongated particle hadn't any effects on the stability of aspahltic mixtures ( $\mathrm{Li}$ and Kett 1967). Some mixtures containing flaky aggregate particles have shown larger fatigue life than mixtures without any flaky particles (Chen, Chang, and Lin 2005). Huber and Heimen found that up to $19 \%$ flaky and elongated particles don't affect volumetric properties of asphaltic mixtures (Huber and Heiman 1987). Stephens and Sinha have suggested optimum amounts of flaky, elongated and cubical aggregates that can cause the highest strength (Stephens and Sinha 1978). Siswosoebrotho et al. have noted that increase in flaky particles content causes decreasing resilient modulus, Marshal Stability and workability, but it can improve moisture damage properties (Siswosoebrotho, Ginting and Soedirdjo 2005). Ganapati and Adiseshu have investigated the effect of aggregate shape factors on the volumetric properties and stability of Dense Bitumen Macadam (DBM) mixtures by testing mixtures containing different amounts of cubical, disk, rod and blade form aggregates. Their results showed that stability, flow, voids filled with asphalt (VFA) increase due to increase in blade shape aggregates content and air voids and voids in mineral aggregate (VMA) decrease due to increase in blade shape aggregates content. Mixtures that only $20 \%$ of whose coarse aggregates had been substituted with cubical, disk, rod and blade shape aggregate exhibited the highest stability and also mixtures containing all cubical particles showed greater stability than mixtures containing all blade, rod, and disk shape aggregate (Ganapati and Adiseshu 2013).

The shape of aggregate is evaluated using simple equipment as each particle is evaluated separately. These methods are time consuming and all of aggregate shape characteristics couldn't be evaluated. New methods using processing and analyzing digital scans that provide rapid and accurate methods of shape factors determination are now available (Yue, Bekking and Morin 1995; Tutumluer, Pan and Carpenter 2005; BessaBranco and Soares 2012). 


\section{Materials}

Crushed limestone coarse, fine and filler from Namin quarry have been used for fabrication of the specimens. Table 1 shows the properties of the aggregate used in this research. Specimens were prepared according to D4 and D5 gradations of ASTM-D3515 standard with maximum nominal size of 19 and $12.5 \mathrm{~mm}$, respectively, which are common gradations for binder and wearing course in Iran. Aggregates are mixed so the gradations of mixtures locate within the middle of the standard limits. Figure 3 shows the gradations of the mixtures used in this research.

The 85/100 penetration grade bitumen, produced by Pasargad oil company (Tabriz refinery), has been used for making the specimens. Table 2 shows the properties of the bitumen.

\section{Experimental Plan}

Prior to fabrication of the specimens, the flaky particles of the coarse fraction of aggregate were separated following BS 812 Part105 test method. Then specified amounts of flaky particles were added to each mixture to achieve mixtures containing $0,25,50,75$ and $100 \%$ of flaky particles content. Marshall specimens were prepared at the laboratory using 75 blows on each side at the optimum bitumen content. Optimum bitumen content was $4.1 \%$ for D4 gradation mixture and $4.9 \%$ for D5 gradation mixture. Volumetric properties of fabricated specimens such as air voids content and VMA were calculated. Stability of the specimens was determined using Marshal Apparatus. Uniaxial static creep test was carried out on each specimen following the BS 598 part 111 test method. Creep is time dependent deformation of material under the stress. Through the static creep test, a specified static, vertical stress is applied to the specimen and continued for a specific period during which the vertical strain is measured. The creep stiffness of the mixture is calculated using the following equation:

$$
S_{m}=\frac{\sigma}{\varepsilon_{(t, T)}}
$$

In which, $S_{m}$ is the creep stiffness, $\sigma$ is the applied stress level, and $\varepsilon_{(t, T)}$ is the strain level after time $t$ and in temperature $T$. 
Van de Loo et al. applied static creep test results to predict the rut depth in asphalt pavements using the following equation (Van de Loo 1974).

$$
R_{d}=C_{m} \times H_{0} \times \frac{\sigma_{a v}}{S_{m}}
$$

In which, $R_{d}$ is the estimated rut depth in $m m, C_{m}$ is the coefficient for considering the dynamic effects of loading ranging from 1 to $2, \mathrm{H}_{0}$ is the thickness of asphaltic layer in $\mathrm{mm}, \sigma_{\mathrm{av}}$ is the average stress level applied on pavement in MPa, and $\mathrm{S}_{\mathrm{m}}$ is the creep stiffness modulus of the asphaltic mixture in MPa.

The specimens were loaded for 1 hour by a vertical stress level of $98 \mathrm{kPa}$, and the vertical deformation of each specimen was monitored at specified intervals. After one hour of loading, the load was removed and the recoverable deformation was monitored for 1 hour. The tests were conducted at $45^{\circ} \mathrm{C}$ that was close to the bitumen softening point. In this temperature, because of softening the bitumen, the role of aggregate characteristics on creep behavior is dominant, which makes it easier to study the effects of aggregate properties on the creep.

\section{Results and Discussion}

A summary of the test results are shown in Table 3. Figures 4 and 5 show the variation of air voids content and VMA with flaky particles content. As they show, for both gradations, the air voids content and VMA increase due to increase in the flaky particles content, indicating that using cubical aggregate in the mixture results in a denser mixture. This is attributed to the difficulty of compaction and the decrease in workability due to increasing the flaky particles. However, the air voids content and VMA of the D5 gradation mixture is more sensitive to the flaky particles content. The D5 gradation is finer than the D4 gradation, which results in more number of flaky particles at the same percentage of flaky particles content. Existence of more flaky particles will intensify their effect on the reduction of workability and increase of air voids content. Mixtures with high amount of air voids tend to further compaction under applied traffic loads and are more likely to the occurrence of rutting.

Figure 6 shows the Marshall stability of the mixtures containing different amounts of flaky particles. According to the figure, flaky particles cause decrease in Marshall Stability. The Marshall stability of D4 and D5 gradation mixtures containing $100 \%$ of flaky particles, are respectively, $36 \%$ and $28 \%$ less than that of the mixture 
without any flaky particles. As mentioned earlier, the decrease in Marshall stability due to increasing flaky particles content can be attributed to the effect of flaky particles on the air voids content and also unstable positioning of the aggregate as well as unsuitable interlocking between the aggregate. The increase in air voids content cause decrease in Marshall Stability. The Marshal stability of the mixtures made of D4 and D5 gradation without any flaky particles decreases by approximately 36 and 28\%, respectively, when are made by $100 \%$ of flaky particles. It can also be seen that the mixtures made by gradation D4 have higher Marshall Stability than the D5 gradation mixtures, which is due to the coarser particles of the D4 gradation.

Figures 7 and 8 show the static creep test results of the mixtures containing different amounts of flaky particles, where the accumulated strain during the period of loading and after removing the load is plotted against time. Similar to the creep recovery behaviour of elasto-visco-plastic materials, there is an instant deformation after applying the load, after which, the strain increases at a decreasing rate, reaching to a steady state rate of deformation. Once the load is removed, there is an instant recovered strain followed by some time dependent recovered strain, which is level off after a certain time elapsed from the instant of removing the load. The difference between the instant strain after applying the load and that of recovered after removing the load is known as time independent plastic strain. The time independent plastic strain occurs, generally, as a result of aggregate particles displacement upon applying the load, which is affected by the aggregate gradation, particles surface texture, angularity and shape, and air voids content. The summation of time dependent and time independent plastic strain results in rutting. The difference between the time dependent accumulated strain during the loading period and the time dependent recovered strain after removing the load is known as time dependent plastic or visco-plastic strain. The time dependent visco-plastic strain occurs, generally, due to the shear deformation of asphaltic binder, which is mainly affected by binder properties, temperature and loading time. However, the physical properties of aggregate and the volumetric properties of the mixture are also effective. As it can be seen, for both gradations, the accumulated strain during the time of loading and after removing the load increases due to increasing the flaky particles content. However, the difference between the mixtures is mostly due to the difference between the strains occurred immediately after applying the load, in which the densification due to the higher air voids content has the major contribution. After the initial densification, the rate of deformation of the mixtures containing different amounts of flaky particles is not significantly different. This can 
be described by relating the shear deformation of the mixture to that occurred in the binder, which is not significantly affected by the shape of aggregate particles. It can also be seen that the D4 gradation mixtures are stiffer than those with the gradation of D5, which was also seen in the Marshall Stability results. In general, asphaltic mixtures with coarser aggregate particles are more resistant against deformation.

The effect of flaky particles on accumulated vertical strain after 1 hour loading is shown in Figure 9. It can be recognized that the accumulated vertical strains are greater for the mixtures with higher amount of flaky particles, and the accumulated vertical strain of the mixtures containing more than $25 \%$ of flaky particles, is significantly higher than those without any flaky particles. The results in Figure 9 also show that the accumulated vertical strain of the mixtures made by finer gradation of D5 is more sensitive to the flaky particles content than that of the mixtures with gradation type D4 which is coarser.

The accumulated vertical strain of D4 and D5 gradation mixtures containing $100 \%$ of flaky particles are respectively 107 and $80 \%$ higher than the control mixture, which is due to both the increased air voids content and unstable positioning of the flaky particles.

After unloading, a fraction of the accumulated strain will recover and the rest that is unrecoverable will be considered as permanent strain. Figure 10 shows the ratio of recoverable vertical strain to the accumulated vertical strain for each mixture. As it can be seen, the ratio is higher for the mixtures containing no flaky particle than the mixtures containing higher amounts of flaky particles, indicating that the mixtures with higher flaky particles content are more vulnerable to permanent deformation. This can be attributed to the increase in air voids content resulted from the flaky particles and decreasing the contact between the particles by separation with the extra binder in between, leading to a higher shear deformation which is mostly unrecoverable after removing the load.

Creep stiffness modulus as defined in Equation (1) is an indication of the mixture resistance against permanent deformation. Figure 11 shows plot of the creep stiffness modulus against flaky particles content. As it can be seen, flaky particles cause decrease in the creep stiffness modulus of the mixtures. The creep stiffness modulus of the mixtures containing $100 \%$ flaky particles is approximately $50 \%$ of that of the control mixture without any flaky particles. 
After conducting the tests, specimens were cut diametrically to investigate the arrangement of the particles. Figures 12.a and 13.a show, respectively, particles arrangement for the D4 and D5 gradation mixtures without any flaky particles, and Figures 12.b and 13.b show, respectively, particles arrangement for the D4 and D5 gradation mixtures containing $100 \%$ of flaky particles. As they show, most of the flaky particles in compacted specimens tend to stay horizontally, which confirms the findings of Oduroh et al. (Oduroh, Mahboub and Anderson 2000).

\section{Conclusions}

In this research, in order to investigate the effects of flaky particles content on the Marshall stability, creep behavior and volumetric properties of asphaltic mixtures, specimens with various flaky particles content and two different gradation type (D4 and D5 gradations of ASTM-D3515 standard) were made. Creep behavior of the mixtures was examined using uniaxial static creep test following BS 598 Part 111 test method. Also volumetric properties and Marshall Stability of the specimens were determined. The following conclusions can be drawn from this paper:

- Increase in flaky particles content causes increasing volume of air voids in mineral aggregate (VMA) and air voids content of the mixtures.

- Flaky particles cause decrease in Marshall stability, creep stiffness modulus and recoverable strain and increase permanent deformation potential.

- Mixtures with finer nominal maximum size of aggregate are more sensitive to flaky particles.

- Most of the flaky particles tend to stay horizontally due to compaction. 


\section{References}

American Society for Testing and Materials, Annual Book of ASTM Standards, 2005. Vol. 04.03, Standard Test Method for Flat Particles, Elongated Particles, or Flat and Elongated Particles in Coarse Aggregate, D4791 (1999), Philadelphia, PA.

American Society for Testing and Materials, Annual Book of ASTM Standards, 2005. Vol.04.03, Specification for Standard Specification for Hot-Mixed, Hot-Laid Bituminous Paving Mixtures, D3515 (2001), Philadelphia, PA.

Barrett, P. J. 1980. The Shape of Rock Particles, A Critical Review. Sedimentology, 27: 291-303.

Bessa, L. S., Branco, V. T. F. C., Soares, J. B. 2012. Evaluation of different digital image processing software for aggregates and hot mix asphalt characterizations. Journal of Construction and Building Materials, 37: 370-378.

British Standards Institution, Methods for determination of particle shape, 812 Part 105., Section 105.1 Flakiness index (1989).

British Standards Institution, Method for determination of resistance to permanent deformation of bituminous mixtures subject to unconfined uniaxial loading, 598 Part 111 (1995).

Brown, E. R., McRae, J. L., and Crawley, A. B. 1989. Effect of aggregate on performance of bituminous concrete. ASTM STP 1016, Philadelphia, 34-63.

Chen, J. S., Chang, M. K., and Lin, Y. K. 2005. Influence of coarse aggregate shape on the strength of asphalt concrete mixtures. Journal of the Eastern Asia Society for Transportation Studies, 6: 1062 - 1075.

Cominsky, R. J. 1994. The Superpave Mix Design Manual for New Construction and Overlays. SHRP-A-407. Strategic Highway Research Program, National Research Council, Washington, DC.

Ganapati N., P. and Adiseshu, S. 2013. Influence of Coarse Aggregate Shape Factors on Bituminous Mixtures. International Journal of Engineering Research and Applications (IJERA) 1(4): 2013-2024.

Huber, G. A., and Heiman, G. H. 1987. Effect of asphalt concrete parameters on rutting performance: a field investigation. Proceedings of Association of Asphalt Paving Technologists, 56:33-61.

Krutz, N. C., and Sebaaly, P. E. 1993. Effect of aggregate gradation on permanent deformation of asphaltic concrete. Proceedings of Association of Asphalt Paving Technologists, 62:450-473.

Li, M. C., and Kett, I. 1967. Influence of coarse aggregate shape on the strength of asphalt concrete mixtures. Highway Research Record 178: $93-106$.

Masad, E., Little, D., Tashman, L., Saadeh, S., Al-Rousan, T., and Sukhwani, R. 2003. Evaluation of aggregate characteristics af fecting HMA concrete performance. Report ICAR 203 for Project Number 203 Federal Highway Administrations (FHWA), Texas Transportation Institute.

Oduroh, P. K., Mahboub K. C., and Anderson R. M. 2000. Flat and Elongated Aggregates in Superpave Regime. ASCE Journal of Materials Engineering. 12(2): 124-130.

Prowell, B. D., Zhang, J. and Brown, E. R. 2005. Aggregate Properties and the Performance of Superpave-Designed Hot Mix Asphalt. Transportation Research Board 539, TRB, National Research Council, Washington, D. C.

Roberts, F. L., Kandhal, P. S., Lee D., and Kennedy T.W. 1991. Hot Mix Asphalt Materials, Mixture Design and Construction. National Asphalt Pavement Association, Lanham, MD.

Siswosoebrotho, B. I., Ginting, K., and Soedirdjo, T. L. 2005. Workability and resilient modulus of asphalt concrete containing flaky aggregates shape. Journal of the Eastern Asia Society for Transportation Studies, 6: 1302 - 1312 .

Stephens, J. E., and Sinha K. C. 1978. Effect of Aggregate Shape on Bituminous Mi x Character. Proceedings, Association of Asphalt Paving Technologists, 47: 434-456.

Tutumluer, E., Pan, T., and Carpenter, S. H. 2005. Investigation of aggregate shape effects on hot mix performance using an image analysis approach. Project Report Number UILU-ENG-2005-2003 University of Illinois at Urbana-Champaign Urbana, IL

Van de Loo, R. J. 1974. Creep testing, a simple tool to judge asphalt stability. Proc of the Association of Asphalt Paving Technologists, A.A.P.T., 43: 253-284.

Vavrik, W. R., Fries R. J., and Carpenter S. H. 1999. Effect of Flat and Elongated Coarse Aggregate on Characteristics of Gyratory Compacted Samples. Transportation Research Record 1681, Transportation Research Board, National Research Council, Washington, DC, 28-36.

Yue, Z., Bekking, W., and Morin, I. 1995. Application of digital image processing to quantitative study of asphalt concrete microstructure. Transportation Research Record 1492, 53-60. 
Table 1: Aggregate properties

\begin{tabular}{|l|c|c|c|}
\hline \multicolumn{1}{|c|}{ Materials } & $\begin{array}{c}\text { Coarse } \\
\text { Properties } \\
\text { (tests) }\end{array}$ & $\begin{array}{c}\text { Fine } \\
\text { aggregate }\end{array}$ & Filler \\
\hline Los Angeles Abrasion Test (ASTM-C131) & 5 & - & - \\
\hline Plasticity Index (ASTM-D4318) & - & N.P. & N.P. \\
\hline Angularity in two sides \% (ASTM-D5821) & 97 & - & - \\
\hline Loss in Magnesium Sulfate Solution \% (ASTM-C88) & 1 & 1 & - \\
\hline Water Absorption \% & 1.0 & 1.6 & - \\
\hline Relative Density (ASTM-C127,128,D854) & 2.656 & 2.617 & 2.791 \\
\hline
\end{tabular}


Table 2: The properties of the bitumen used in this research

\begin{tabular}{|l|c|c|}
\hline \multicolumn{1}{|c|}{ Test } & Standard & Results \\
\hline Density at $25^{\circ} \mathrm{C}\left(\mathrm{g} / \mathrm{cm}^{3}\right)$ & ASTM-D70 & 1.010 \\
Penetration at $25^{\circ} \mathrm{C}(0.1 \mathrm{~mm})$ & ASTM -D5 & 87 \\
Softening Point $\left({ }^{\circ} \mathrm{C}\right)$ & ASTM-D36 & 48 \\
Ductility at $25^{\circ} \mathrm{C}(\mathrm{cm})$ & ASTM-D113 & $>100$ \\
Solubility in Trichloroethylene $(\%)$ & ASTM-D2042 & 99.99 \\
Flash Point $\left({ }^{\circ} \mathrm{C}\right)$ & ASTM-D92 & 304 \\
Kinematic Viscosity at $120^{\circ} \mathrm{C}(\mathrm{cSt})$ & ASTM-D2170 & 556 \\
Kinematic Viscosity at $135^{\circ} \mathrm{C}$ ( $\left.\mathrm{cSt}\right)$ & ASTM-D2170 & 325 \\
Kinematic Viscosity at $160^{\circ} \mathrm{C}(\mathrm{cSt})$ & ASTM-D2170 & 95 \\
Loss in weight after thin film oven test $(\%)$ & ASTM-D1754 & 0.02 \\
\hline
\end{tabular}


Table 3: Static creep test, stability and volumetric properties results

\begin{tabular}{|c|c|c|c|c|c|c|c|c|c|}
\hline $\begin{array}{c}\text { Mixture } \\
\text { gradation }\end{array}$ & $\begin{array}{c}\text { Aggregate } \\
\text { flakiness } \\
\text { index } \\
\%\end{array}$ & $\begin{array}{c}\text { Accumulated } \\
\text { strain after } \\
\text { one hour of } \\
\text { loading \%o }\end{array}$ & $\begin{array}{c}\text { Permanent } \\
\text { strain afte } \\
\text { one hour of } \\
\text { unloading \%o }\end{array}$ & $\begin{array}{c}\text { Recoverable } \\
\text { strain after } \\
\text { one hour of } \\
\text { unloading } \\
\% \circ\end{array}$ & $\begin{array}{c}\text { Ratio of } \\
\text { recoverable } \\
\text { to } \\
\text { accumulated } \\
\text { strain \% }\end{array}$ & $\begin{array}{c}\text { Creep } \\
\text { stiffness } \\
\text { modulus } \\
\text { (MPa) }\end{array}$ & $\begin{array}{c}\text { Marshall } \\
\text { stability } \\
\text { (kgf) }\end{array}$ & $\begin{array}{c}\text { Air voids } \\
\text { content } \\
\%\end{array}$ & $\begin{array}{c}\text { VMA } \\
\%\end{array}$ \\
\hline & 0 & 3.5 & 2.6 & 0.9 & 26 & 28 & 1600 & 3.6 & 12.5 \\
D4 & 25 & 4.6 & 3.7 & 0.9 & 20 & 22 & 1330 & 3.9 & 12.9 \\
& 50 & 4.3 & 3.3 & 1.0 & 23 & 23 & 1240 & 4.0 & 12.8 \\
& 75 & 4.9 & 4.1 & 0.8 & 16 & 20 & 1030 & 4.1 & 12.8 \\
& 100 & 6.3 & 5.5 & 0.8 & 13 & 15 & 1020 & 4.2 & 13.0 \\
\hline & 0 & 4.2 & 3.3 & 0.9 & 21 & 23 & 1260 & 4.0 & 14.5 \\
D5 & 25 & 4.0 & 3.2 & 0.8 & 20 & 25 & 1060 & 4.0 & 14.6 \\
& 50 & 6.9 & 5.8 & 1.1 & 16 & 14 & 950 & 4.6 & 15.1 \\
& 75 & 7.1 & 5.9 & 1.2 & 17 & 14 & 940 & 4.6 & 15.1 \\
& 100 & 8.7 & 8.1 & 0.6 & 7 & 11 & 910 & 5.2 & 15.6 \\
\hline
\end{tabular}




\section{Figure Captions:}

Figure 1: Components of an aggregate shape

Figure 2: Two type of stable (a) and unstable (b) particles

Figure 3: The gradation of the mixtures

Figure 4: Air voids vs. flaky particles content

Figure 5: Voids in Mineral aggregate (VMA) vs. flaky particles content

Figure 6: Marshall Stability vs. flaky particles content

Figure 7: Time dependent vertical strain of D4 gradation mixture containing various contents of flaky particles

Figure 8: Time dependent vertical strain of $\mathrm{D5}$ gradation mixture containing various contents of flaky particles

Figure 9: Accumulated vertical strain after 1 hour loading vs. flaky particles content

Figure 10: Ratio of recoverable vertical strain after 1 hour unloading to accumulated vertical strain vs. flaky particles content

Figure 11: Creep stiffness modulus vs. flaky particles content

Figure 12: Particles arrangement for D4 gradation mixtures (a) mixture containing no flaky particle (b) mixture containing $100 \%$ flaky particles

Figure 13: Particles arrangement for D5 gradation mixtures (a) mixture containing no flaky particle (b) mixture containing $100 \%$ flaky particles 


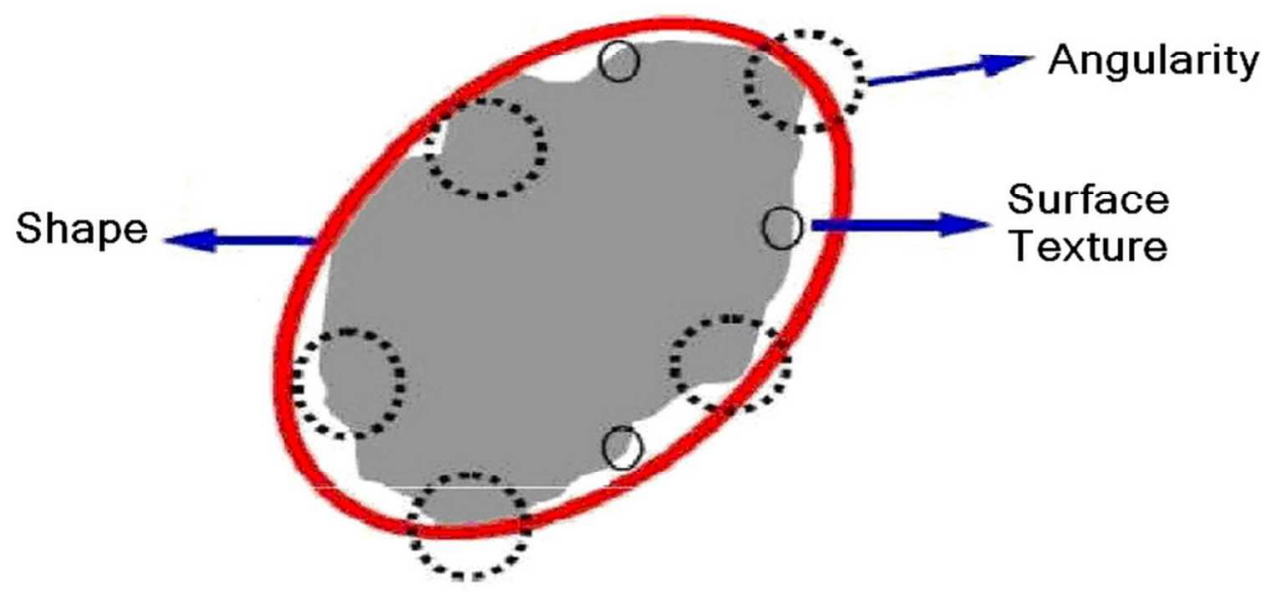

Components of an aggregate shape $358 \times 191 \mathrm{~mm}(72 \times 72$ DPI $)$ 


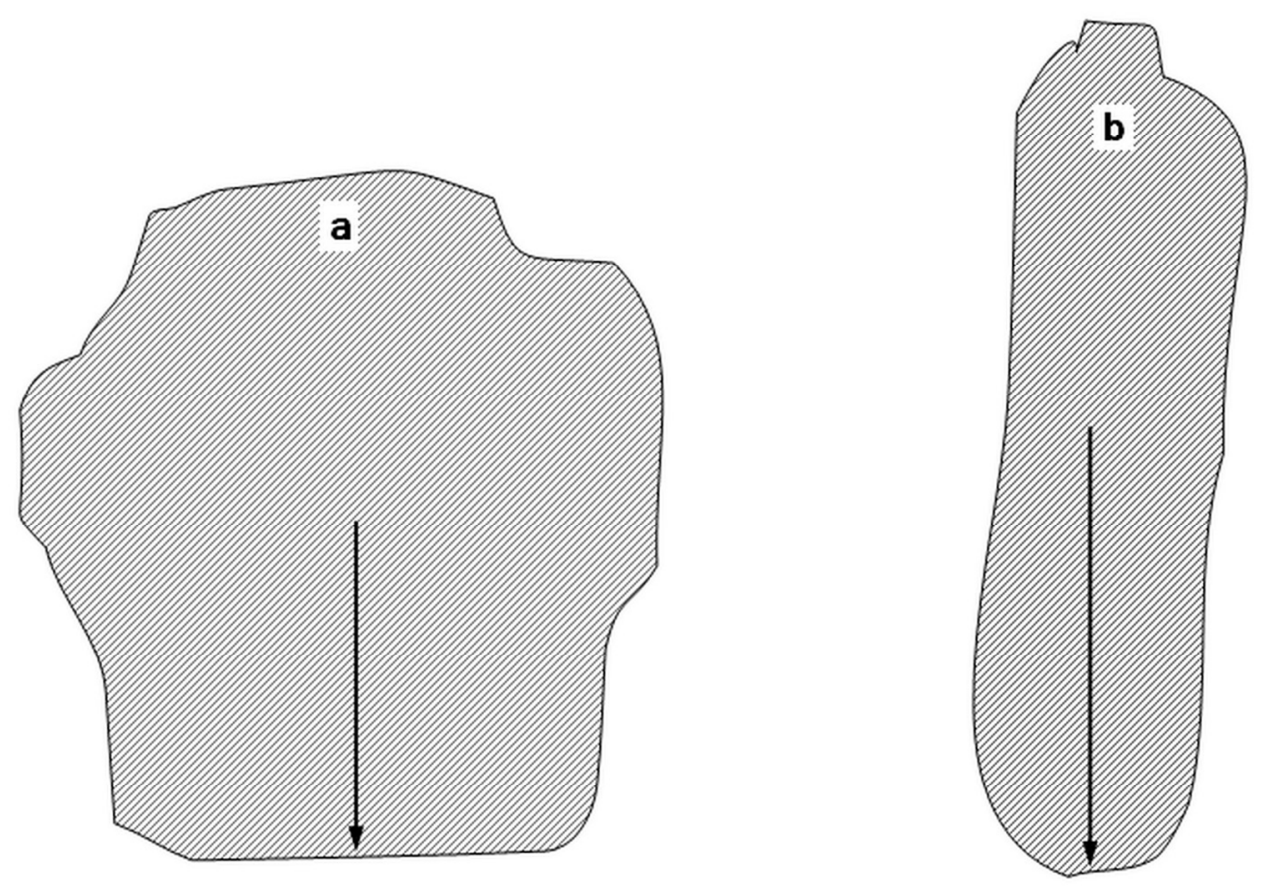

Two type of stable (a) and unstable (b) particles $512 \times 358 \mathrm{~mm}(72 \times 72$ DPI $)$ 


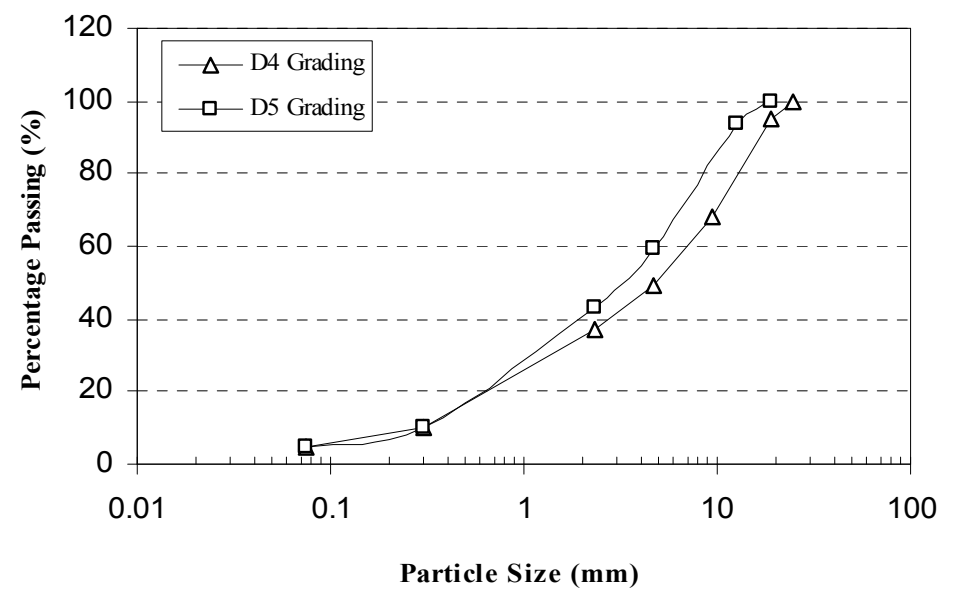

https://mc06.manuscriptcentral.com/cjce-pubs 


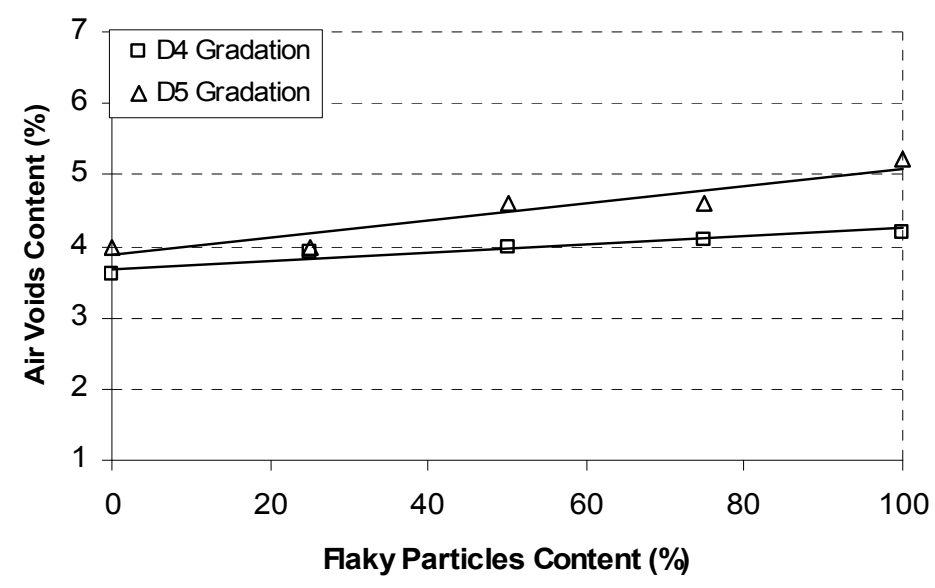

https://mc06.manuscriptcentral.com/cjce-pubs 


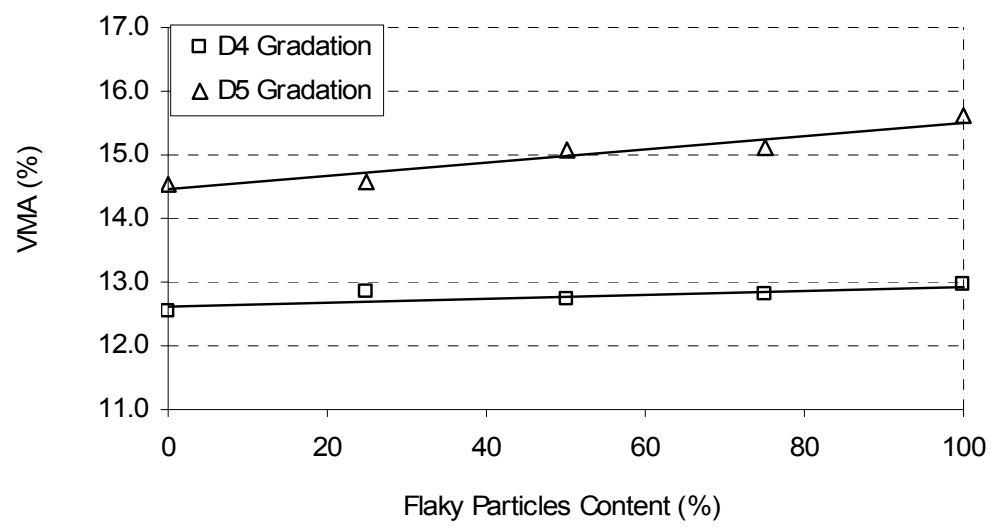

https://mc06.manuscriptcentral.com/cjce-pubs 


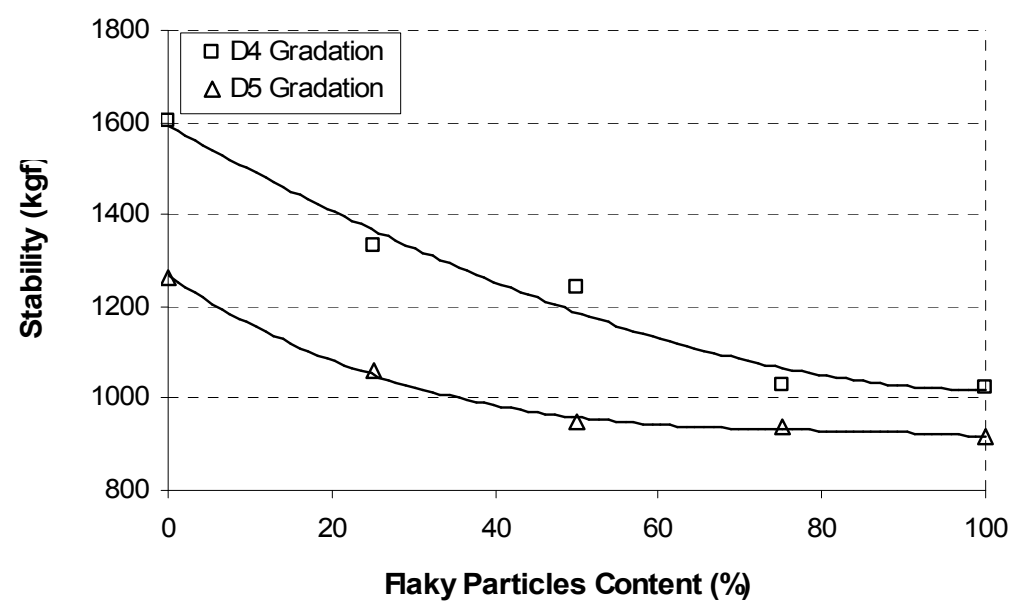

https://mc06.manuscriptcentral.com/cjce-pubs 


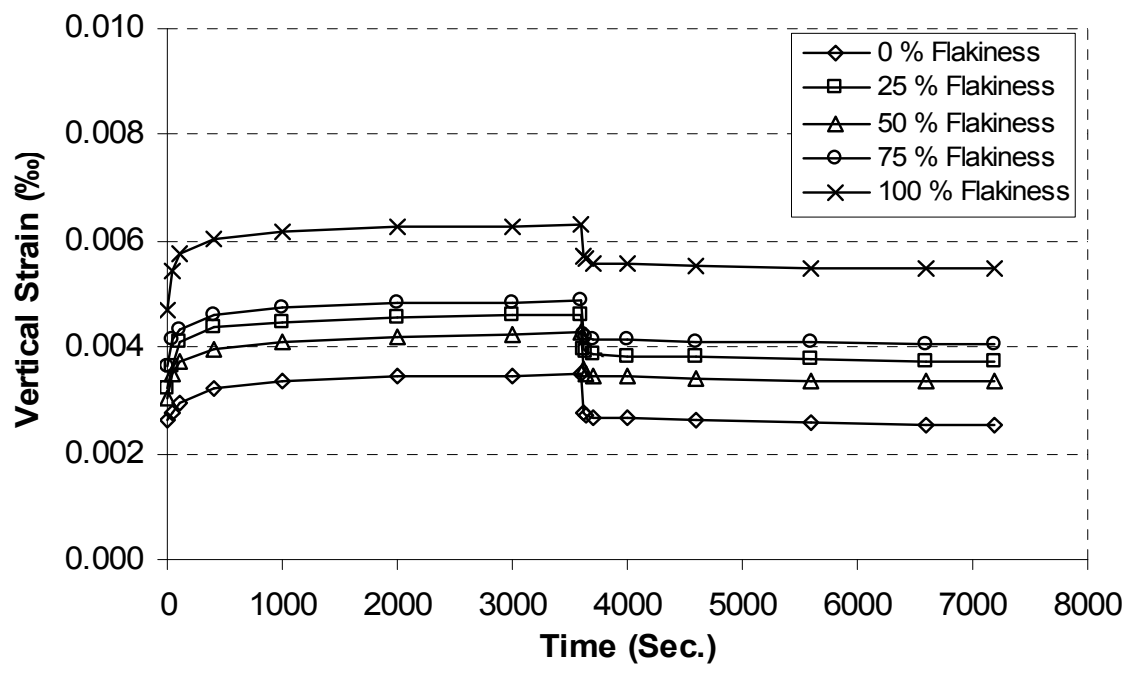

https://mc06.manuscriptcentral.com/cjce-pubs 


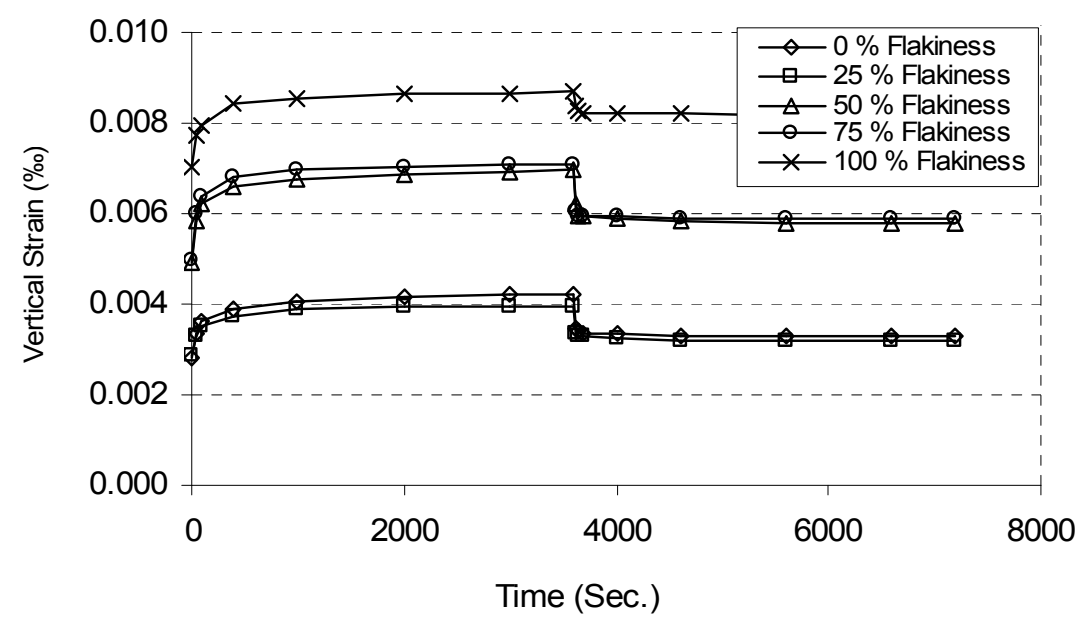

https://mc06.manuscriptcentral.com/cjce-pubs 


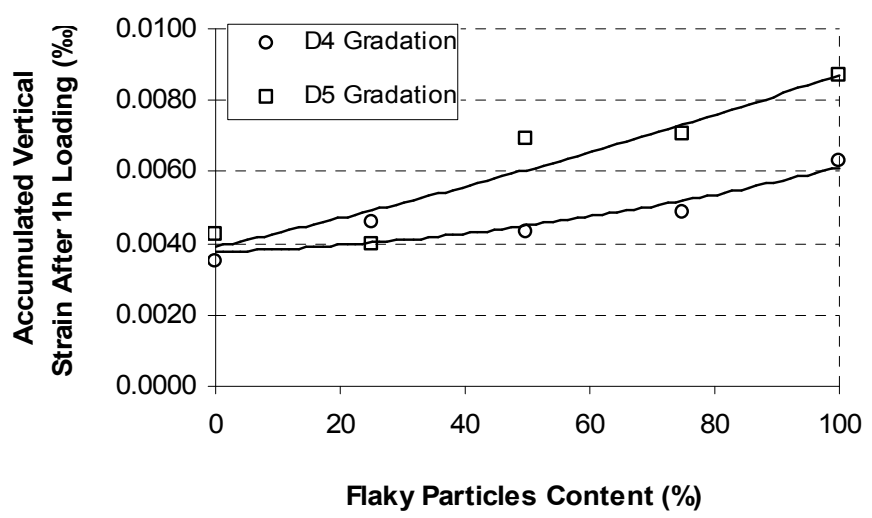

https://mc06.manuscriptcentral.com/cjce-pubs 


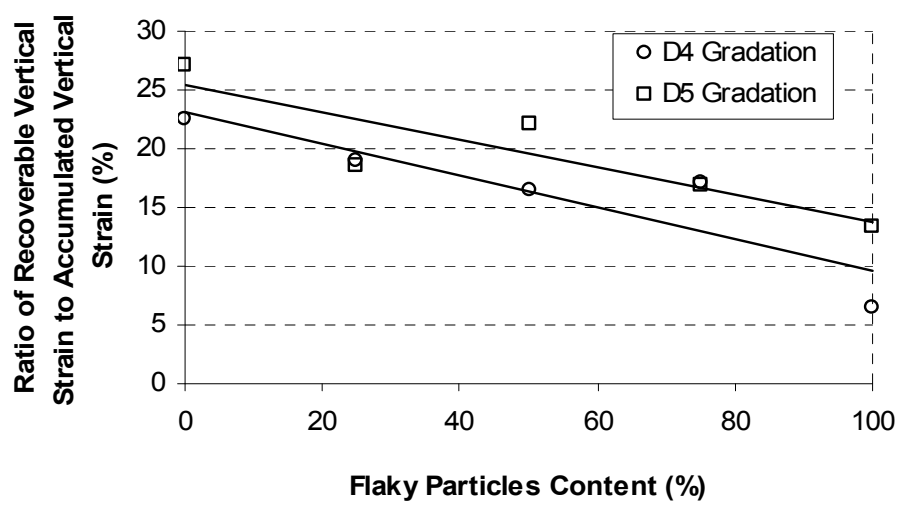

https://mc06.manuscriptcentral.com/cjce-pubs 


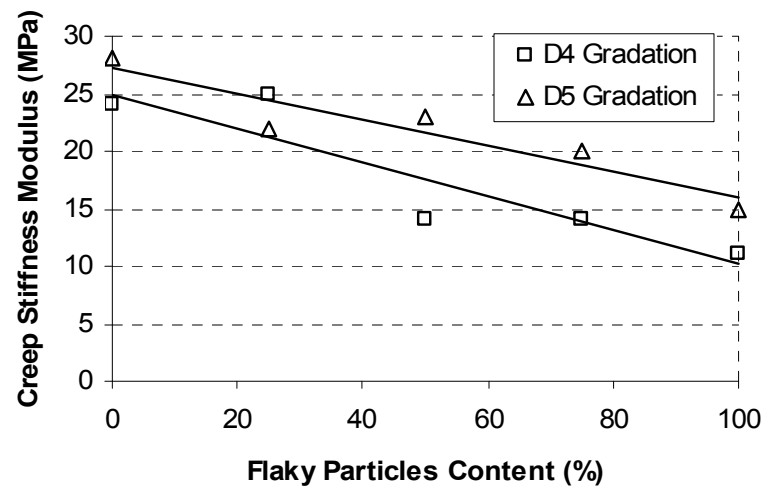

https://mc06.manuscriptcentral.com/cjce-pubs 

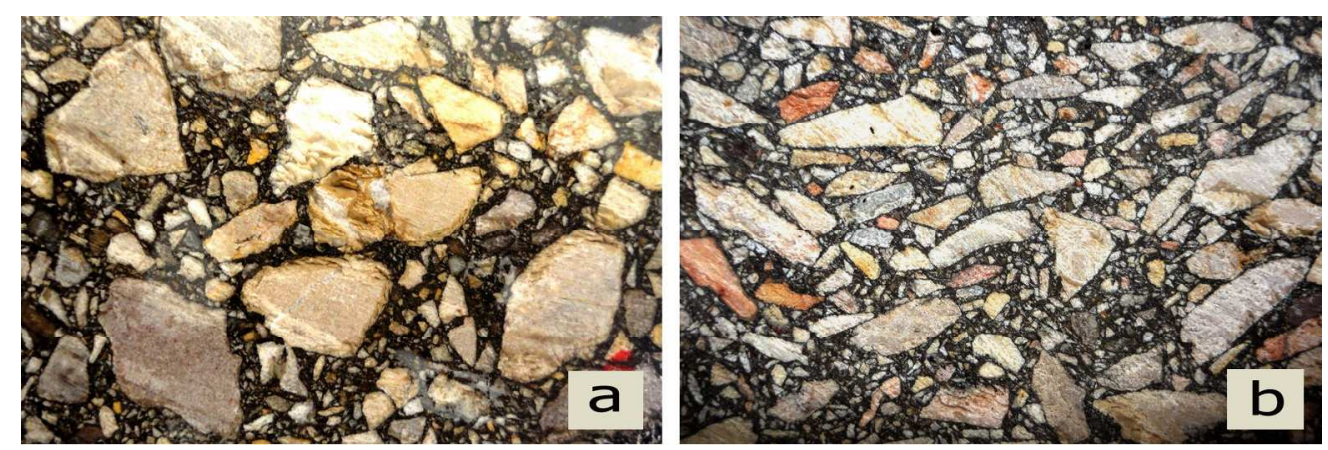

Particles arrangement for D4 gradation mixtures (a) mixture containing no flaky particle (b) mixture containing $100 \%$ flaky particles $182 \times 60 \mathrm{~mm}(300 \times 300 \mathrm{DPI})$ 


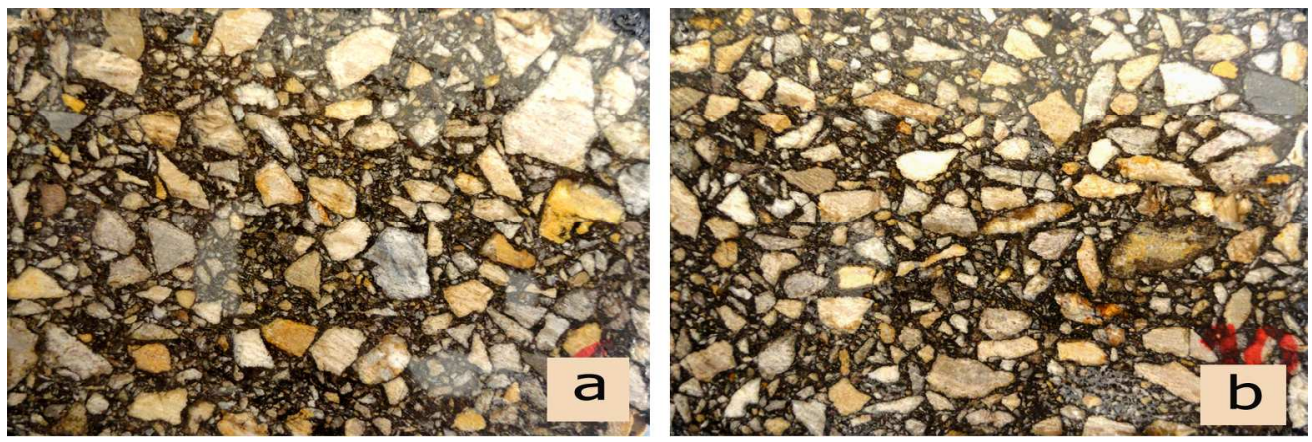

Particles arrangement for D5 gradation mixtures (a) mixture containing no flaky particle (b) mixture containing $100 \%$ flaky particles $182 \times 60 \mathrm{~mm}(300 \times 300 \mathrm{DPI})$ 